\title{
Mineral Particles Found on the Hairs of Holy Maria-Magdalena Studied by Scanning Electron Microscopy and Elemental Analysis
}

\author{
Gérard Lucotte \\ Institute of Molecular Anthropology, Paris, France \\ Email: lucotte@hotmail.com
}

How to cite this paper: Lucotte, G. (2020) Mineral Particles Found on the Hairs of Holy Maria-Magdalena Studied by Scanning Electron Microscopy and Elemental Analysis. Open Journal of Applied Sciences, 10, 41-59.

https://doi.org/10.4236/ojapps.2020.103004

Received: November 27, 2019

Accepted: February 28, 2020

Published: March 3, 2020

Copyright $\odot 2020$ by author(s) and Scientific Research Publishing Inc. This work is licensed under the Creative Commons Attribution International License (CC BY 4.0).

http://creativecommons.org/licenses/by/4.0/

\begin{abstract}
The presumed hairs of Holy Maria-Magdalena are studied here for mineral particles found on their surfaces, by the techniques of scanning electron microscopy coupled with energy dispersive X-ray. Exploration by these techniques of the hair surfaces allows us to observe and study some marble fragments that can originate from the walls of the sarcophagus in which Maria-Magdalena's remains were kept. These new findings support the authenticity of the hair as traditionally reported in the French "tradition des Saints de Provence".
\end{abstract}

Keywords

Maria-Magdalena's Hair, Scanning Electron Microscopy, Energy Dispersive X-Ray, Marble Fragments, Mineral Particles

\section{Introduction}

According to the French "Tradition des Saints de Provence" [1] Holy Maria-Magdalena (3AD?-63AD?) landed (with her companions) to the French (the Gaule at this era) Mediterranean shores, in a region corresponding to the current part of Les Saintes-Marie-de-la-Mer. Thereafter, she withdrew for thirty years to the cave of La-Sainte-Baume. Her remains are kept in the little town of Saint-Maximin-la-Sainte-Baume; her hairs were kept in a dedicated reliquary in the Saint-Maximin basilica. We have obtained ten of these hair for scientific purposes (microscopic examination and chemical analysis).

In recent years, we have published from this material the mitochondrial DNA haplogroup found by extracting genomic DNA from the bulb of hair number 10 [2] that corresponds to a Jewish woman, and have given an explanation of the 
brown-red observed colour of the hairs by scanning electron microscopic characterisation of its melanosomes [3].

In the present study, we describe and analyse the different sorts of mineral particles found on these hairs. Hair number 9 was specially studied for this purpose.

\section{Material and Methods}

The material is ten hairs from the lock of Maria-Magdalena's hair. These hairs, numbered 1 to 10, were placed on sterile adhesive paper, for SEM (Scanning Electron Microscopy) observation and EDX (Energy Dispersive X-Ray spectroscopy) analysis.

The SEM apparatus used is the FEI model Quanta FEG (an environmental electron microscope). Elemental analysis of the particles on this apparatus, was carried out because it is equipped with the probe model X-flash 6/30. Both LFD (Large Field Detector) and CBS (Circular Back Scattering) procedures were used, the last one to better detect heavy elements. Each elemental analysis is given in the form of a spectrum, with kiloelectrons/Volts $(\mathrm{Ke} / \mathrm{V})$ on the abscissa and elemental peak heights (cps/eV) in ordinates.

\section{Results}

The following figures represent the principal mineral particle species we observed on the hairs. Figure 1 shows two particles of calcite (chemical formula: $\mathrm{CaCO}_{3}$ ) found on the surface of hair number 9. Calcite crystals (with an approximate rhombohedric symmetry) are the most common mineral of calcium carbonate observed on the hair surfaces.

An example of a most rare calcium carbonate observed is represented in the Figure 2 photograph: it is a little (about $10 \mu \mathrm{m}$ of maximal length) particle, with angular outlines, found on the border of the hair number 8. Elemental analysis establishes that it is a calcium carbonate, but with a relatively highly elevated content of calcium (this is a "dense" calcium carbonate). Similar particles are found on the surfaces of hair number 2 (one sample), 3 (two samples), 4 (one sample) and 5 (one sample).

Such particles correspond to marble, as demonstrated by the analysis (Figure 3) of marble powder from marble sold by the Dugay firm, Saint-Ouen.

A relatively common (because found in almost all the hairs studied) other form of calcium carbonate is of the sort shown in Figure 4, which is found on the hair number 9 surface. Elemental analysis establishes that it is a carbonate double, with calcium and magnesium $\left(\mathrm{CaMg} . \mathrm{CO}_{3}\right)$, of the dolomite form. The presence of dolomite minerals on hairs of Maria-Magdalena must be related to the dolomitic geology of some parts of the Sainte-Baume massif and of the neighbouring regions [4].

Concerning the group of minerals based on silicon, Figure 5 shows one example of two montmorillonite/illite (of some clays) particles located on hair 


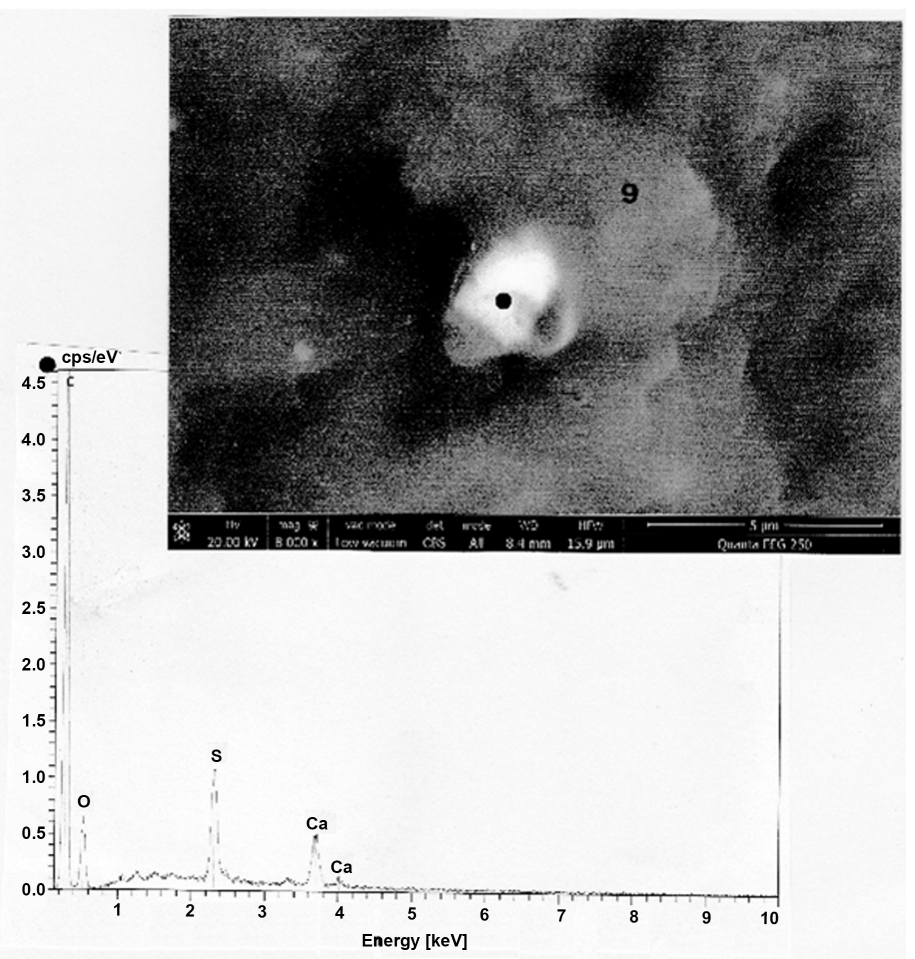

Figure 1. An example of two calcite crystals, located on hair number 9. Above: SEM photograph (in CBS, $8000 \times$ ) of the two crystals; the black point indicates the location where EDX analysis is realized. Below: spectrum at the black point. C: carbon; O: oxygen; S: sulphur; $\mathrm{Ca}$ (two peaks): calcium.

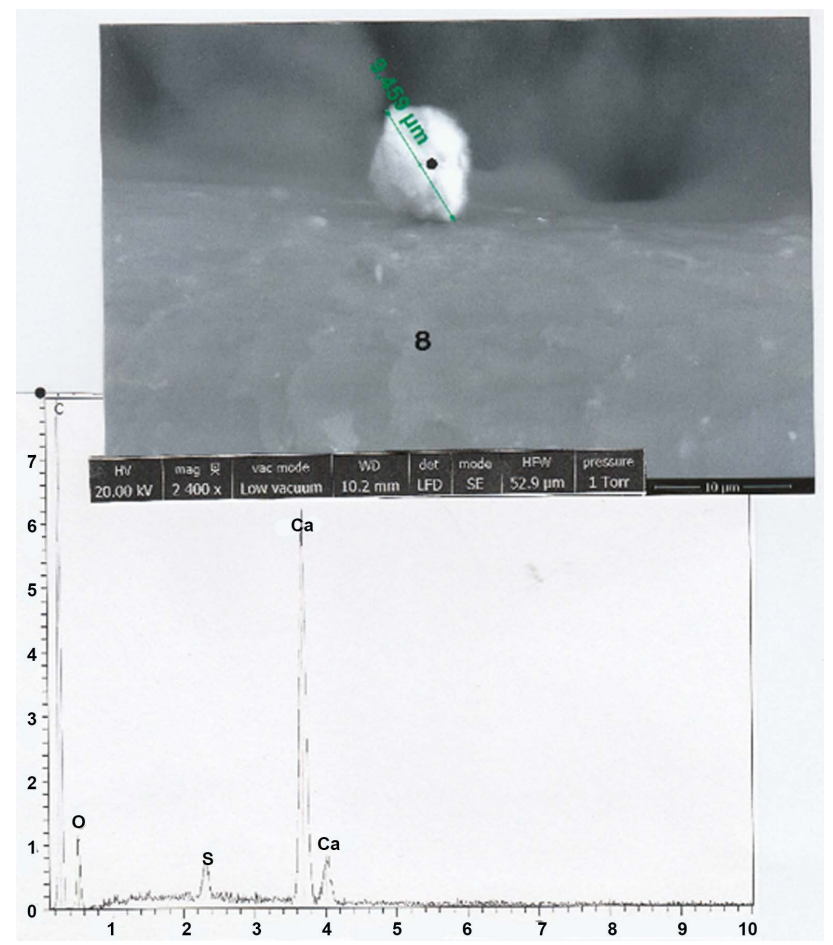

Figure 2. An example of a dense calcium carbonate particle, located on hair number 8. Above: SEM photograph (in LFD, 2400x) of the particle (measurement is in $\mu \mathrm{m}$ ). Below: spectrum at the black point. C: carbon; O: oxygen; S: sulphur; Ca (two peaks): calcium. 


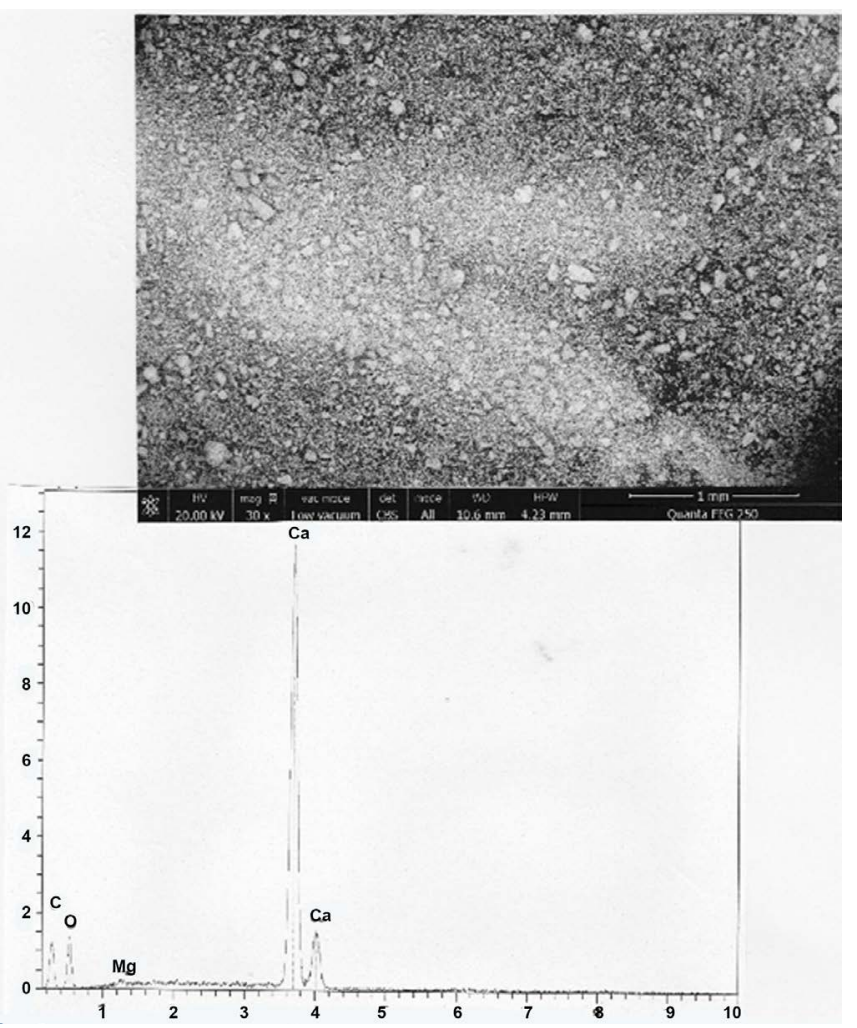

Figure 3. Study of a marble powder sample of reference. Above. SEM photograph (in CBS, 30 $\times$ ) of the powder. Below: global spectrum of the powder. C: carbon; O: oxygen; $\mathrm{Mg}$ (traces): magnesium; $\mathrm{Ca}$ (two peaks): calcium.

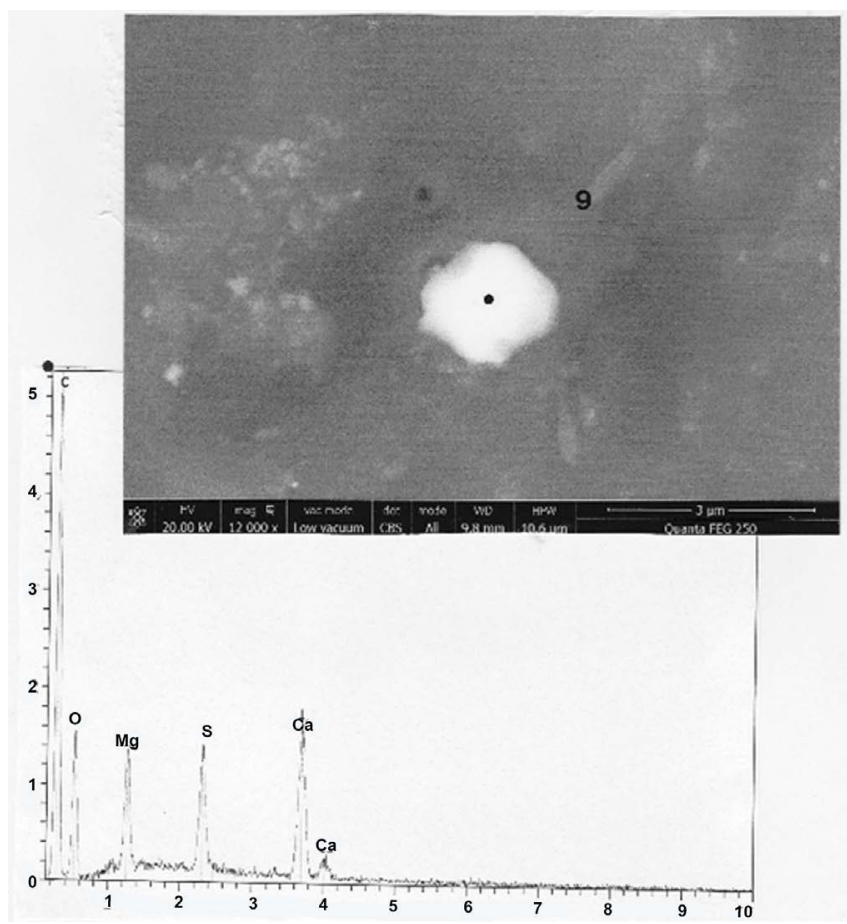

Figure 4. An example of a dolomite crystal, located on hair number 9. Above: SEM photograph (in CBS, 12,000×) of the crystal. Below: spectrum at the black point. C: carbon; O: oxygen; Mg: magnesium; S: sulphur; Ca (two peaks): calcium. 


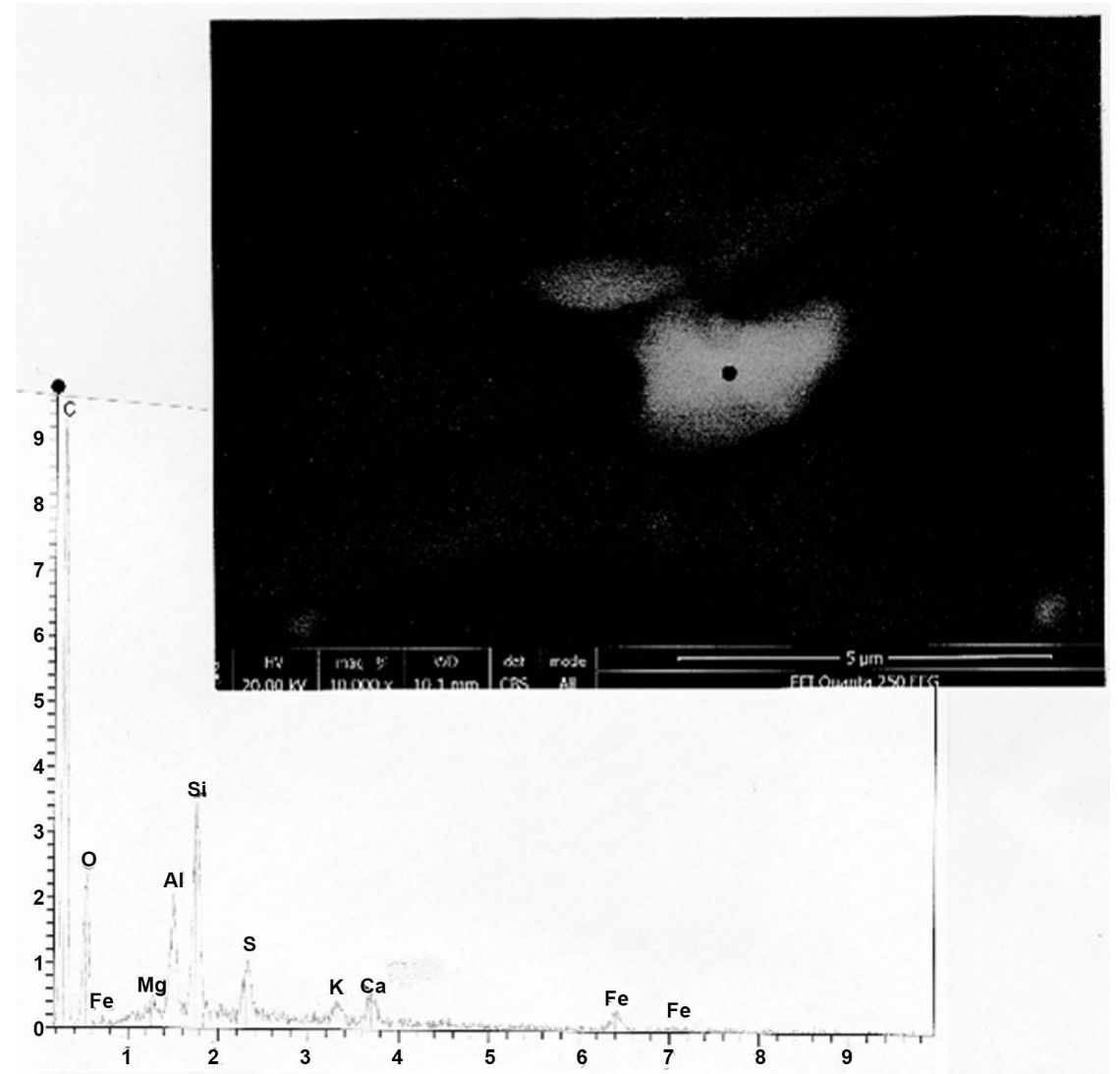

Figure 5. An example of two particles of montmorillonite/illite, located on hair number 2. Above: SEM photograph (in CBS, 10,000x) of the particles. Below. spectrum at the black point. C: carbon; O: oxygen; Fe (three little peaks): iron; Mg: magnesium; Al: aluminium; Si: silicium; S: sulphur; K: potassium; Ca: calcium.

number 2. Such a mineral is a phylosilicate, an aluminosilicate/with calcium and potassium and with iron, very commonly found in hot and tropical regions of the earth. We found numerous samples of montmorillonite, on all the hairs studied.

The rarest aluminosilicate found is that represented in Figure 6 located on hair number 1 . This micro-plaque, of relatively large size (about $50 \mu \mathrm{m}$ of maximal length), is a conglomerate compounded of numerous little particles that are white-to-electrons. Elemental analysis of this plaque establishes that it is an aluminosilicate (with potassium and calcium, and traces of phosphorous and of titanium) with iron, which has a relative abundance of iron oxide giving a red colour to this plaque.

A systematic research concerning presences of this sort of micro-plaque had been undertaken on the hair number 1 - 3 surfaces: there are only four of these plaques on hair number 1, seven on hair number 2, and two on hair number 3. Concerning hair number 9 , there are only four plaques on its surface.

This sort of mineral material was recently found in other samples of hairs of Maria-Magdalena [5]; among the two interpretations retained by the authors to explain such a presence was that it constitutes some sort of hair dying, explaining 


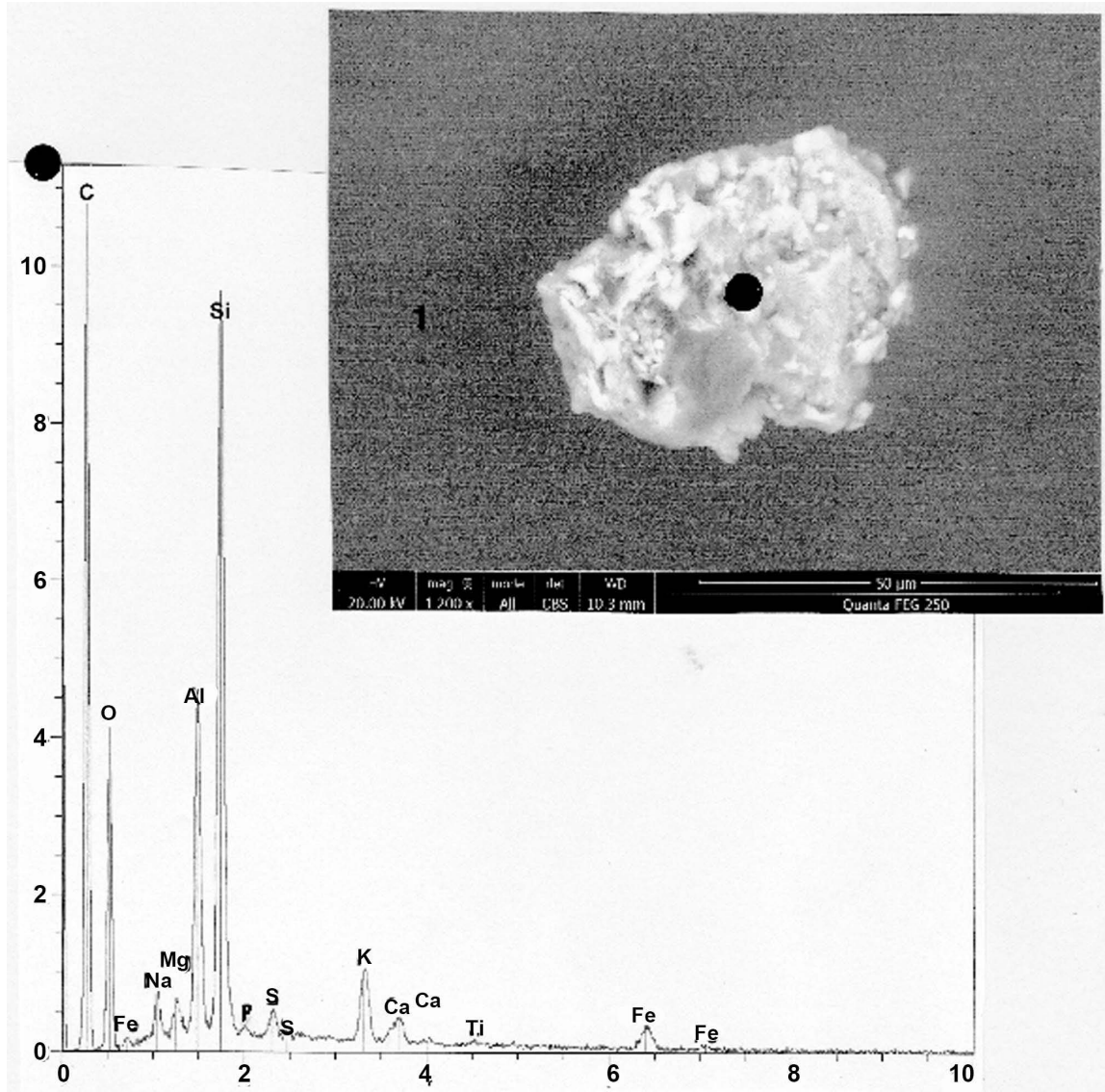

Figure 6. An example of a great particle of an aluminosilicate with iron, located on hair number 1. Above: SEM photograph (in CBS, 1200×) of the particle. Below: spectrum at the black point. C: carbon; O: oxygen; Fe (three peaks): iron; Na: sodium; Mg: magnesium; Al: aluminium; Si: silicium; P: phosphorous; S (two peaks): sulphur; K (two peaks): potassium; Ca (two peaks): calcium; Ti (traces): titanium.

the red colour observed. In fact, the brown-red stain of Maria-Magdalena's hairs is a natural colour [3]; the red plaque pattern observed does not correspond to that usually described in optical and SEM microscopy for hair dying [6].

We note great similarities (both for aspect and composition) between the plaques and the material of a fragment of a brick tile sampled in Olbia (Figure 7), an archaeological site dated back to the First Century located near the town of Hyères (in France): in both cases the morphological aspect (a conglomerate of fine particles coated in a smooth mould) and the chemical composition (an aluminosilicate with potassium and calcium, with traces of phosphorous and titanium, relatively iron-rich) are the same.

So we interpret the aluminosilicate micro-plaques observed on the hair surfaces as accidentally detached brick fragment residues. Interestingly, there are two casings of slabs-one being covered by tiles (roofing tiles) -in the crypt of the Saint-Maximin basilica [7]. We suggest that the brick fragments found on the hairs originate from this sort of tile; they can be seen today in the crypt, where the sarcophagi are displayed. 


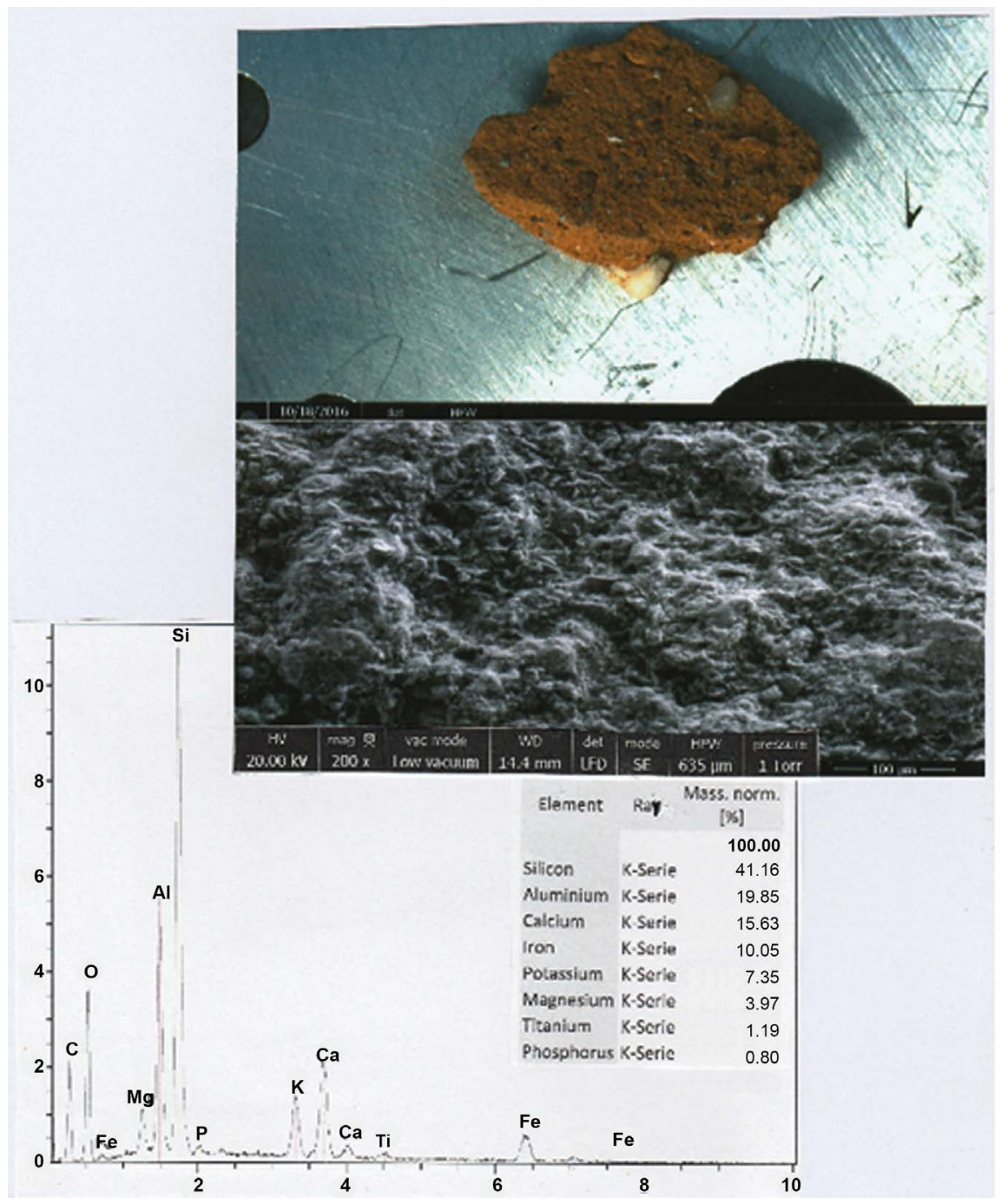

Figure 7. Study of a brick fragment of tile from Olbia. Upper photograph: optical view $(5 \times)$ of the fragment. Lower photograph: SEM photograph (in LFD, 200x) of the fragment surface. Above: global spectrum of the fragment. C: carbon; O: oxygen; Fe (three peaks): iron; Mg: magnesium; Si: silicium; P: phosphorous; K: potassium; Ca (two peaks): calcium; Ti: titanium. Insert shows normalized mass (without carbon and oxygen) of each element.

Figure 8 shows a special particle, located on hair number 9, whose elemental composition is almost entirely of silicon; in this silica $\left(\mathrm{SiO}_{2}\right)$ particle, the amount of silicium is so elevated that it must correspond to a natural quartz. Probably it is a "semi-precious" stone fragment, deposited on hair for some decorative/sanctifying purposes. This sort of particle is rarely found on human hair; in the case of Maria-Magdalena, a systematic research concerning the presence of this sort of particle on all hairs has shown a group of three of such fragments on hair number 2, and another isolated fragment on hair number 4 .

Figure 9 shows an example of another sort of semi-precious stone fragment, located near the border of hair number 9. Its elemental composition corresponds to that of a potassium feldspar [8], a mineral that has nothing to do with the 


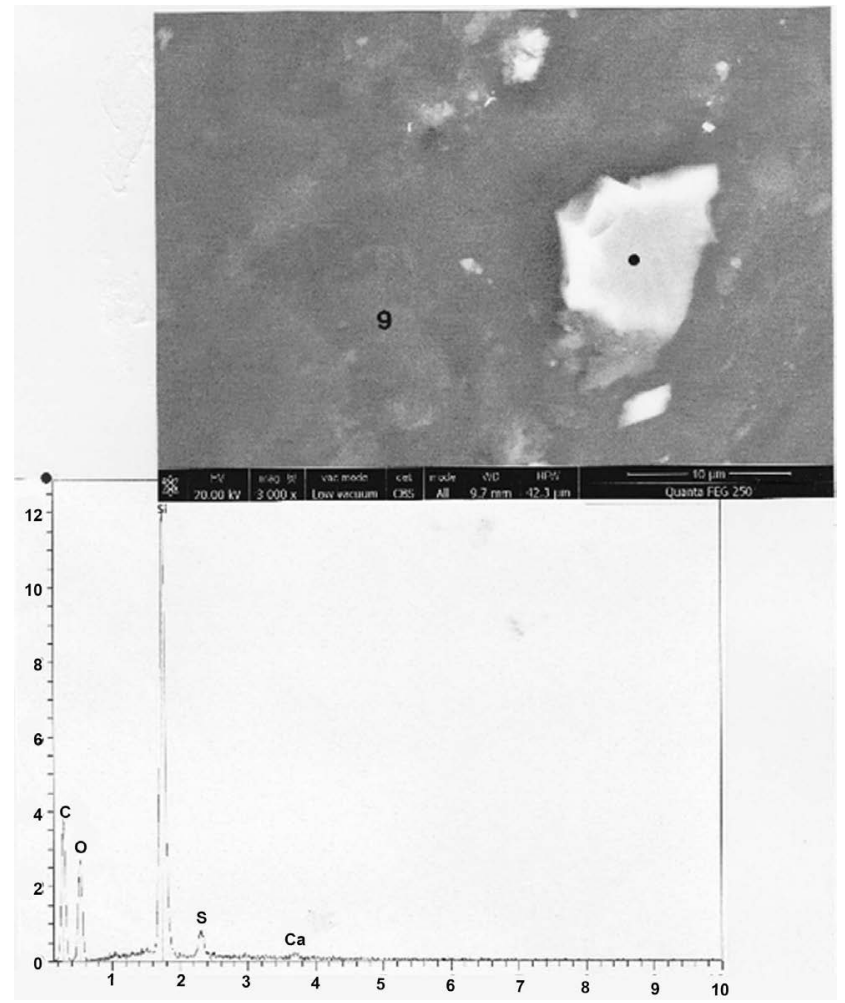

Figure 8. An example of silica particle, located on hair number 9. Above: SEM photograph (in CBS, 3000×) of the particle. Below: spectrum at the black point. C: carbon; O: oxygen; Si: silicium; S: sulphur; Ca (traces): calcium.

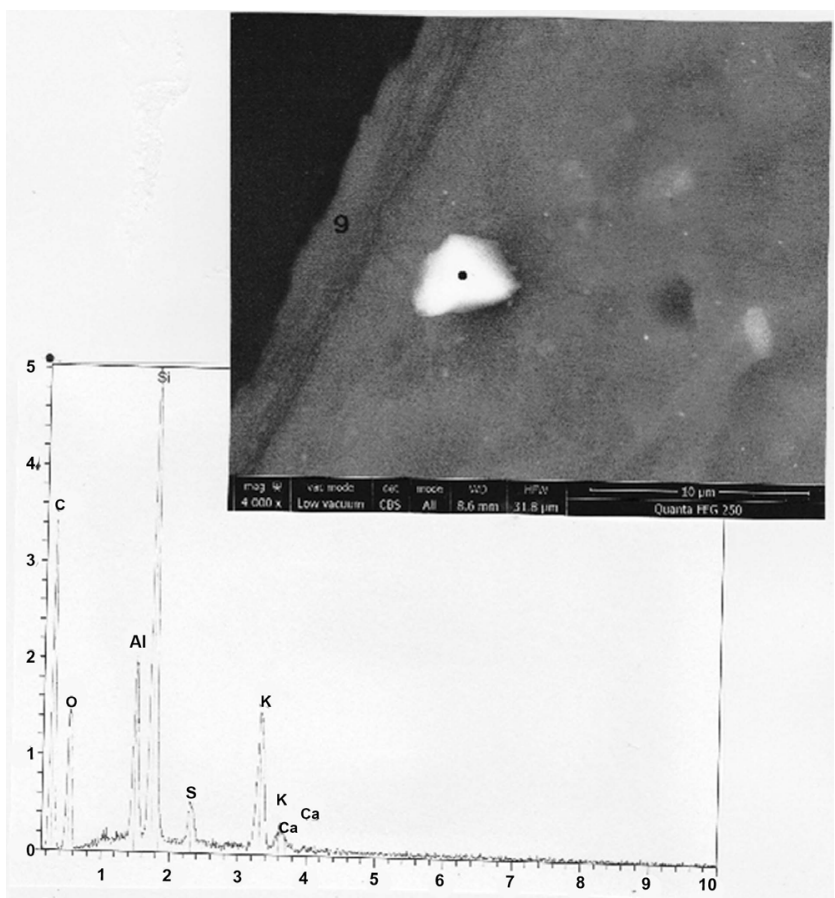

Figure 9. An example of a potassic feldspar particle, located on hair number 9. Above. SEM photograph (in CBS, $4000 \times$ ) of the particle. Below: spectrum at the black point. C: carbon; O: oxygen; Al: aluminium; Si: silicium; S: sulphur; K (two peaks): potassium; Ca (two peaks): calcium. 
usual stones in the geological environment where the hairs are displayed. This potassium feldspar fragment is also a rare mineral deposit on hairs, only one other such fragment (also located on hair number 9) being found.

Finally, Figure 10 shows a quasi-hexagonal matt-to-electrons glass fragment particle, located on hair number 9. It is really a fragment of glass [9] because, unlike the one illustrated in [3] that is less convincing, it is mainly compounded of silicium and aluminium (with an important constituent of sulphur, that may confer a yellow colour to that fragment), and with components of sodium, magnesium, potassium (their oxides are the meltings) and calcium (its oxide is a stabilizer); the relatively highly elevated peak of carbon indicates that it is an ancient (because carbonated) specimen. It possibly originates from the glass of some reliquary where Maria-Magdalena's remains were kept.

\section{Discussion}

Table 1 summarizes the main sorts of minerals (and the corresponding numbers of their particles) that are found on the hairs of Maria-Magdalena. Most of them, like calcite and clays are common minerals of the grounds; dolomite is indicative of the soil of the neighbouring regions of the Sainte-Baume massif, where Maria-Magdalena lived at the end of her life.

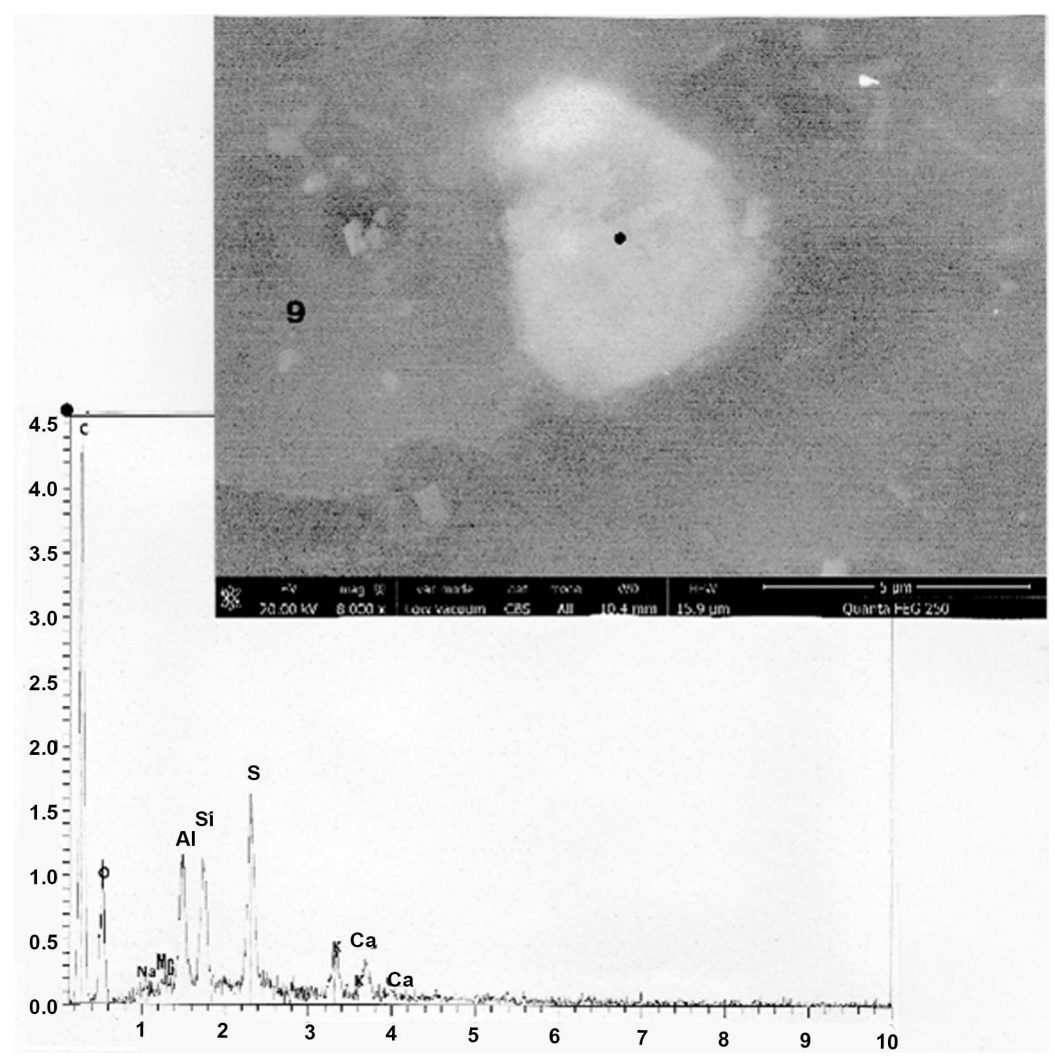

Figure 10. A glass fragment, located on hair number 9. Above: SEM photograph (in CBS, $8000 \times$ ) of the fragment. Below. spectrum at the black point. C: carbon; O: oxygen; Na: sodium; Mg: magnesium; Al: aluminium; Si: silicium; S: sulphur; K (two peaks): potassium; Ca (two peaks): calcium. 
Table 1. The five main mineral species found on the hairs.

\begin{tabular}{cclc}
\hline Categories & Minerals & \multicolumn{1}{c}{ Number of particles found } & $\begin{array}{c}\text { Corresponding } \\
\text { figures }\end{array}$ \\
\hline $\mathbf{1}$ & calcite & $\begin{array}{l}\text { two particles on hair number 9. Up to 30 particles } \\
\text { on hairs. }\end{array}$ & Figure 1 \\
$\mathbf{2}$ & dolomite & $\begin{array}{l}\text { one particle on hair number 9. 21 particles on hairs. } \\
\text { two particles on hair number 2. Up to 80 particles }\end{array}$ & Figure 4 \\
clays & $\begin{array}{l}\text { on hairs } \\
\text { aluminosilicate } 5 \\
\text { one particle on hair number 1. Three others on hair } \\
\text { number 1; seven on hair number 2; two on hair } \\
\text { number 3; four on hair number 9 }\end{array}$ & Figure 6 \\
& silica (quartz) & $\begin{array}{l}\text { one particle on hair number 9. Three on hair } \\
\text { number 2; one on hair number 4 }\end{array}$ & Figure 8 \\
\hline
\end{tabular}

Table 2 lists the six marble particles on the hairs, and characterized as such. One marble particle is located on hair number 2. Two other marble particles are located on hair number 3, the second one being illustrated on Figure 11. The fourth marble particle found, located on the border of hair number 4, is illustrated on Figure 12. Figure 13 shows the marble particle located on the border of hair number 5 .

All the six marble particles found had the three following characteristics: 1) they are relatively big in size (of about $5-10 \mu \mathrm{m}$ of maximal length); 2) with angular outlines; 3 ) with a relatively highly elevated content of calcium. They are very white in SEM photographs (particularly in CBS), that indicates their dense calcium carbonate nature.

The marble fragments observed on some hairs of Maria-Magdalena comprise the main matter to discuss here in relationship to the authenticity of these relics. Four sarcophagi are visible today in the crypt of the Saint-Maximin basilica [7]; the first one, that is now used as the altar support, is referred to as the sarcophagus "de Marie-Madeleine" (designated as such according to the "tradition des Saints de Provence" [4]), because her body was placed into this sarcophagus by Holy Maximin. Figure 14 shows a photograph of this sarcophagus.

Figure 15 shows a SEM photograph of a sample taken from the wall surface of this sarcophagus. Elemental analysis of its main mineral constituent establishes that it is of marble; observed micro-fracture traces on the main marble piece surface indicate that it can be altered easily. Therefore we interpret that the marble fragments observed on the hair surfaces could be detached, over time, from a sarcophagus which is also of marble. That is the case also, although with a greater mineral heterogeneity, for (Figure 16) the said "de Saint Sidoine" sarcophagus (located on the right-hand side of the crypt) according to the "tradition des Saints de Provence" [4], in which Cassianite monks translated (in 716) Maria-Magdalena rests in this sarcophagus for fear of Saracens. Figure 17 shows a photograph of the Saint Sidoine sarcophagus.

Consequently, we consider that marble fragments (because marble is not a so 
Table 2. The six marble particles found on the hairs.

\begin{tabular}{ccc}
\hline Hair numbers & Numbers of particles found & Corresponding figures \\
\hline 2 & one particle & \\
3 & two particles & Figure 11 \\
4 & one particle & Figure 12 \\
5 & one particle & Figure 13 \\
8 & one particle & Figure 2 \\
\hline
\end{tabular}

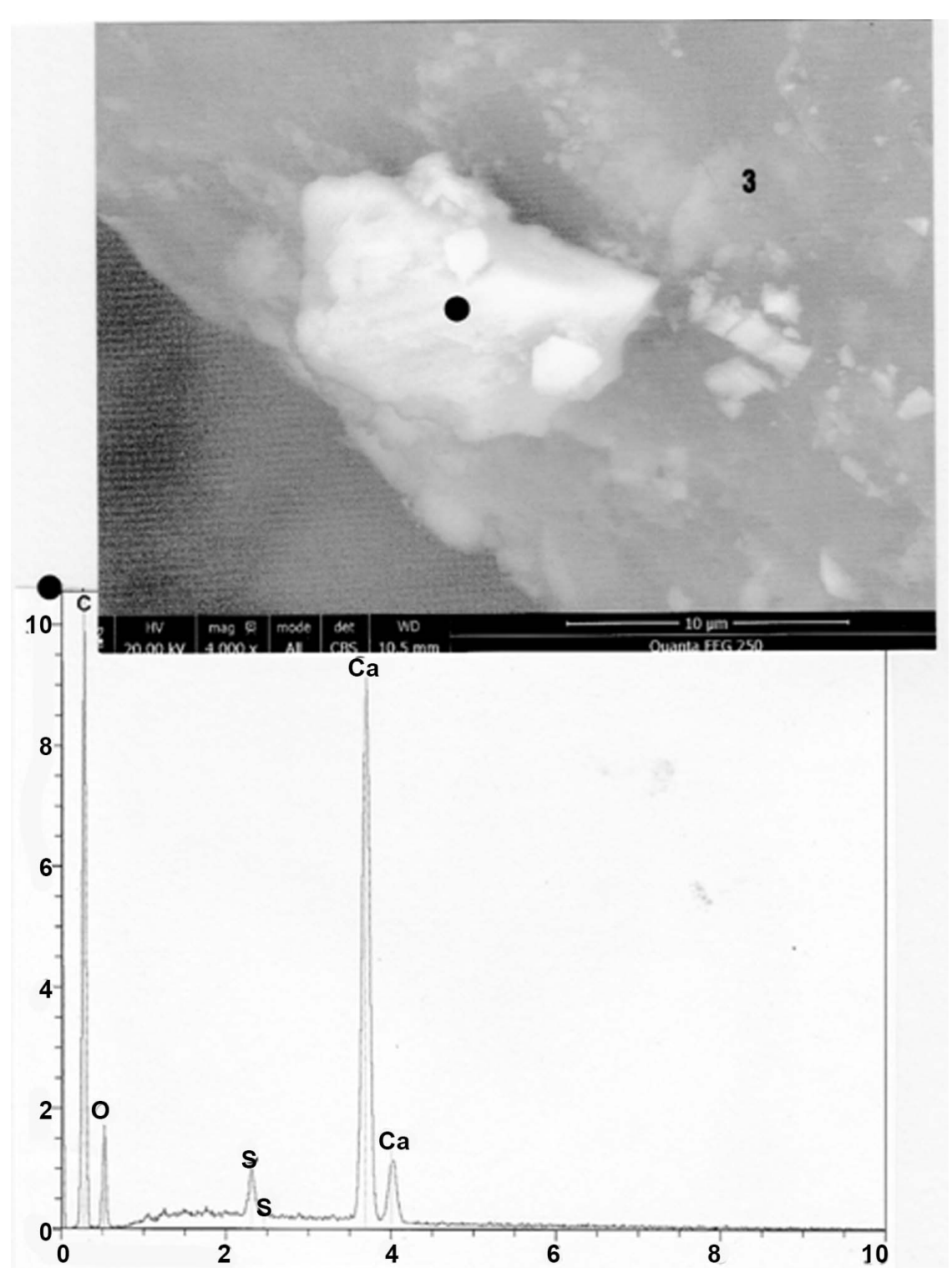

Figure 11. The second marble particle, located on hair number 3. Above: SEM photograph (in CBS, 4000×) of the particle. Below: spectrum at the black point. C: carbon; O: oxygen; S (two peaks): sulphur; Ca (two peaks): calcium.

common material) found on the surface of some of the Maria-Magdalena hairs can originate from these two sarcophagi, and specially from the second one. 


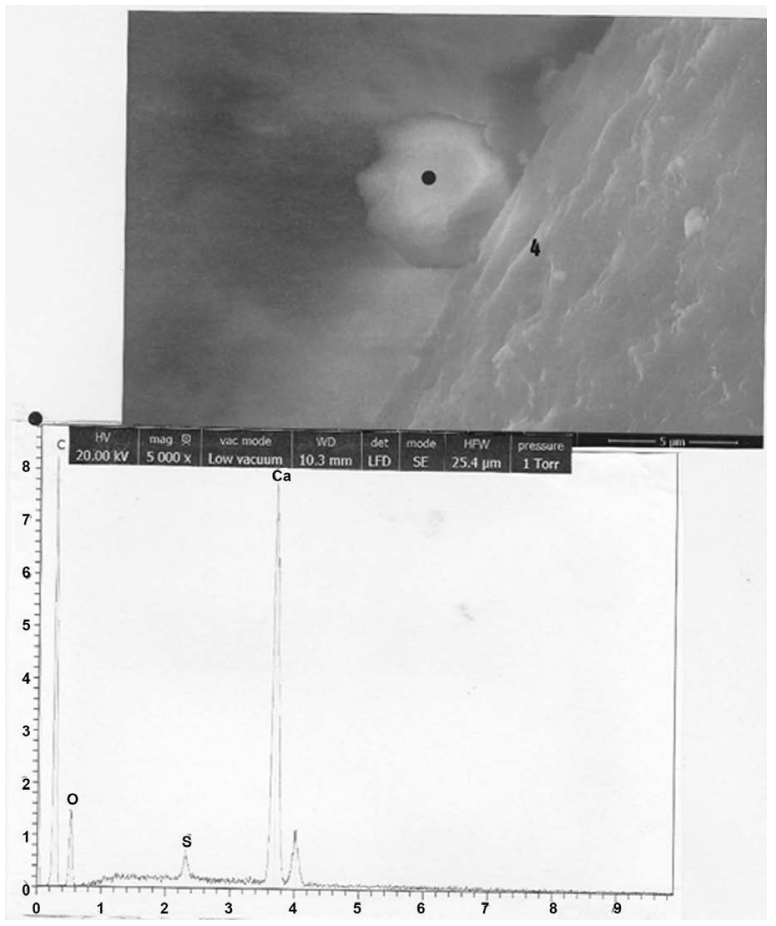

Figure 12. The marble located on the border of hair number 4. Above: SEM photograph (in LFD, 5000x) of the particle. Below: spectrum at the black point. C: carbon; O: oxygen; S: sulphur; $\mathrm{Ca}$ (two peaks): calcium.

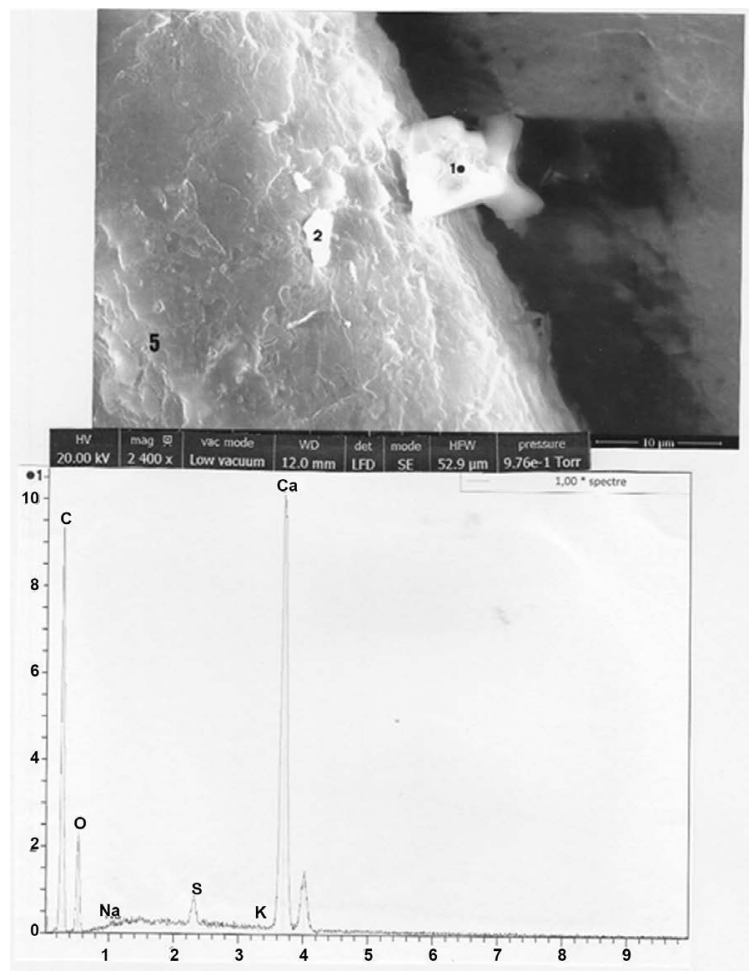

Figure 13. The two (1 and 2) particles, located on the border of hair number 5. Above: SEM photograph (in LFD, 2400x) of the particles. Below: spectrum of 1 at the black point. C: carbon; O: oxygen; $\mathrm{Na}$ (traces): sodium; S: sulphur; K (traces): potassium; Ca (two peaks): calcium. Particle 2 is a gypsum. 


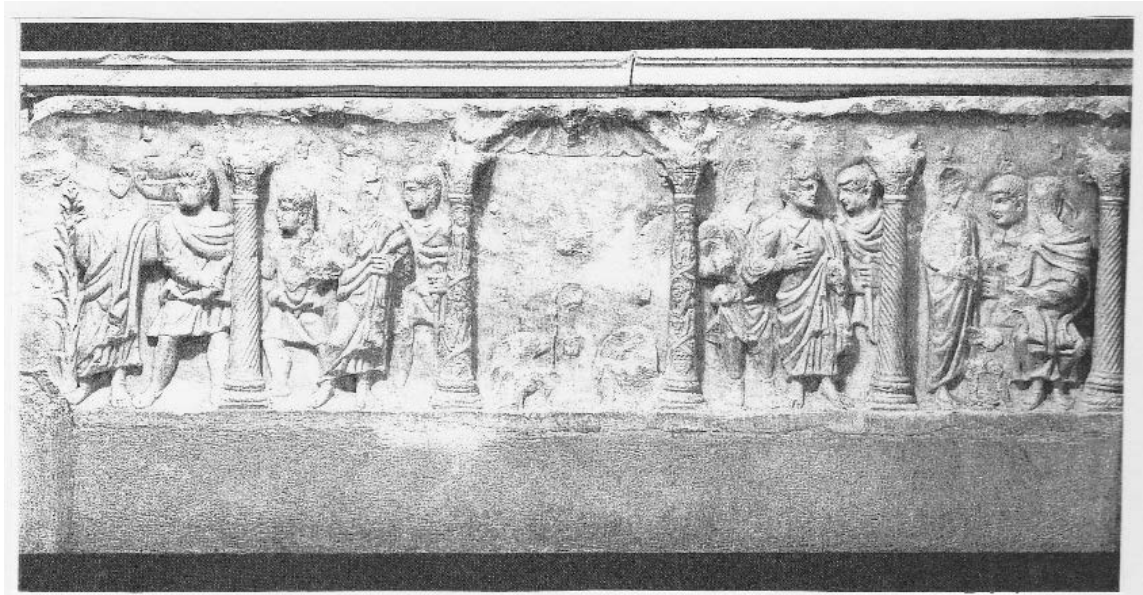

Figure 14. Photograph of the anterior part of the Marie-Madeleine's sarcophagus (from 7).

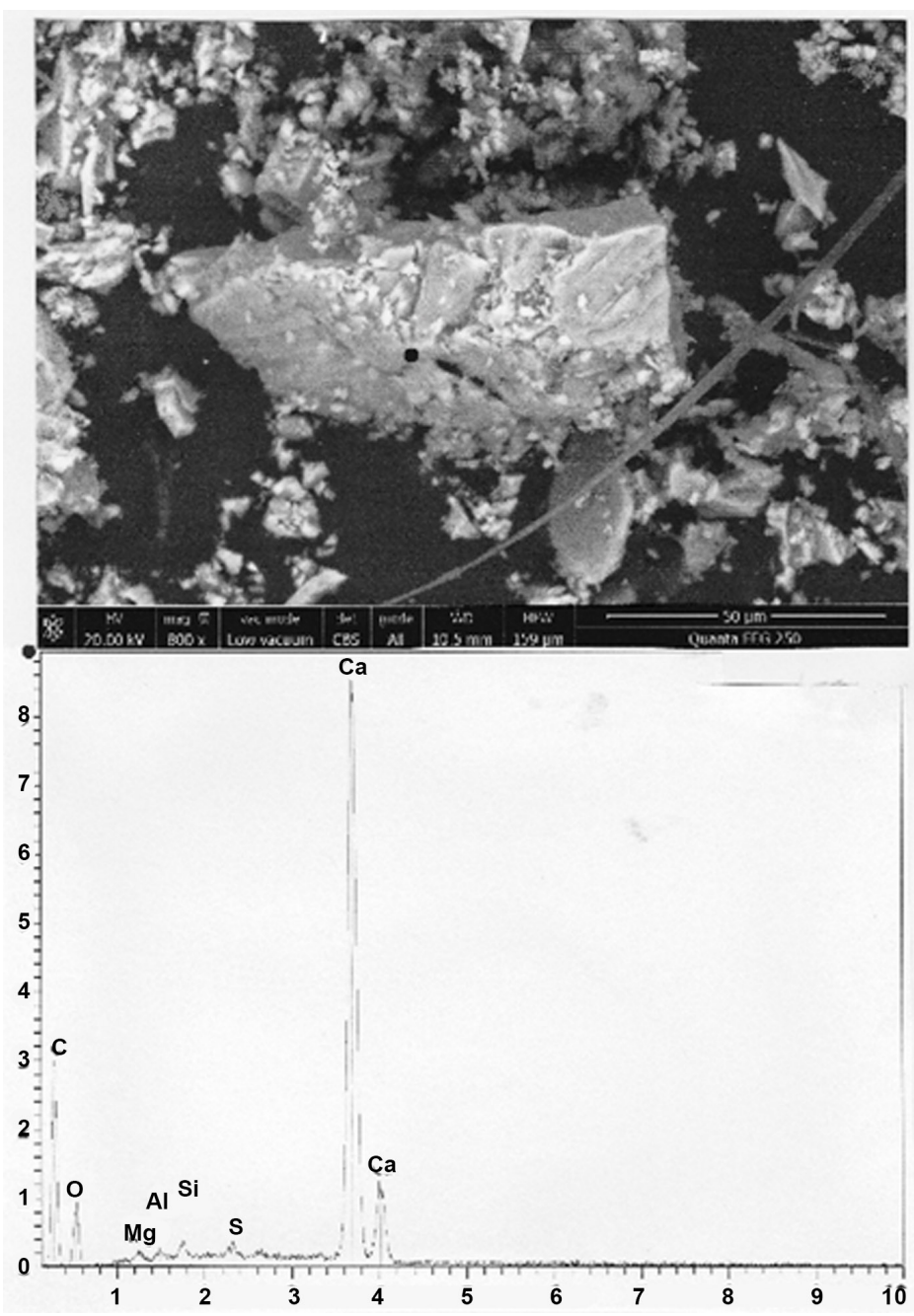

Figure 15. A marble fragment of Marie-Madeleine's sarcophagus. Above. SEM photograph (in CBS, $800 \times$ ) of the fragment. Below. spectrum at the black point. C: carbon; O: oxygen; $\mathrm{Mg}$ (traces): magnesium; $\mathrm{Al}$ (traces): aluminium; Si: silicium; S: sulphur; Ca (two peaks): calcium. 


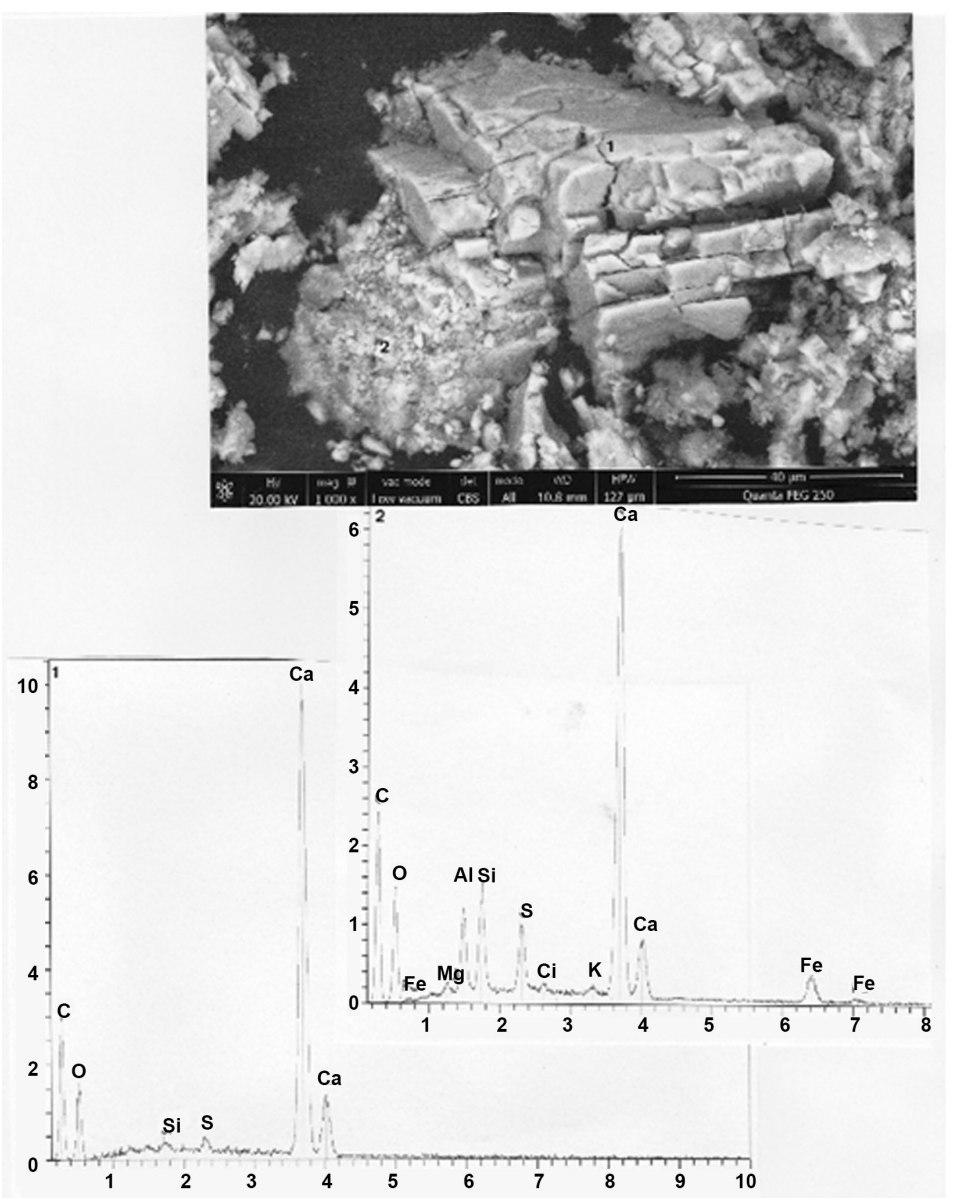

Figure 16. Two marble fragments of the Saint Sidoine sarcophagus. Above: SEM photograph (in CBS, $1000 \times$ ) of the two (1 and 2) fragments. Upper spectrum: spectrum of 2 . Lower spectrum: spectrum of 1 . C: carbon; O: oxygen; Fe (three peaks): iron; Mg: magnesium; Al: aluminium; Si: silicium; S: sulphur; $\mathrm{Cl}$ (traces): chlorine; K (traces): potassium; $\mathrm{Ca}$ (two peaks): calcium.

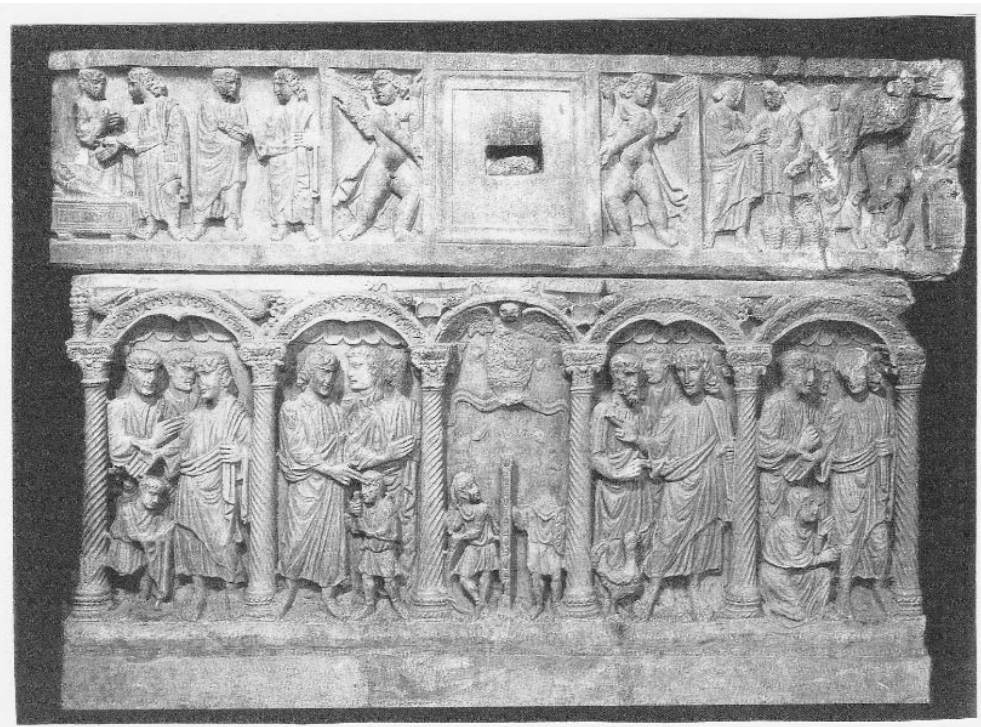

Figure 17. Photograph of the anterior part of the Saint Sidoine's sarcophagus (from 7). 
The high quality of the marble of Marie-Madeleine's sarcophagus can be appreciated in Figure 18, which summarizes the appearance and composition of that marble powder: it is a thin powder, the constituent parts of which are of relatively uniform sizes (of $50 \mu \mathrm{m}$ average size), which must correspond to a very fine grain marble. The marble of this sarcophagus, by its distinctive features (mainly its whiteness, slenderness and translucency), is much purer and more precious than that of the other sarcophagus; it could originate from a quarry located on the borders of the Marmara sea, near Constantinople [4].

Past controversies concerned the exact material of Marie-Madeleine's sarcophagus [4]: Is it of white marble, or of alabaster as cited by some ancient authors? Some of the observed compact mineral particles, like those shown in Figure 19

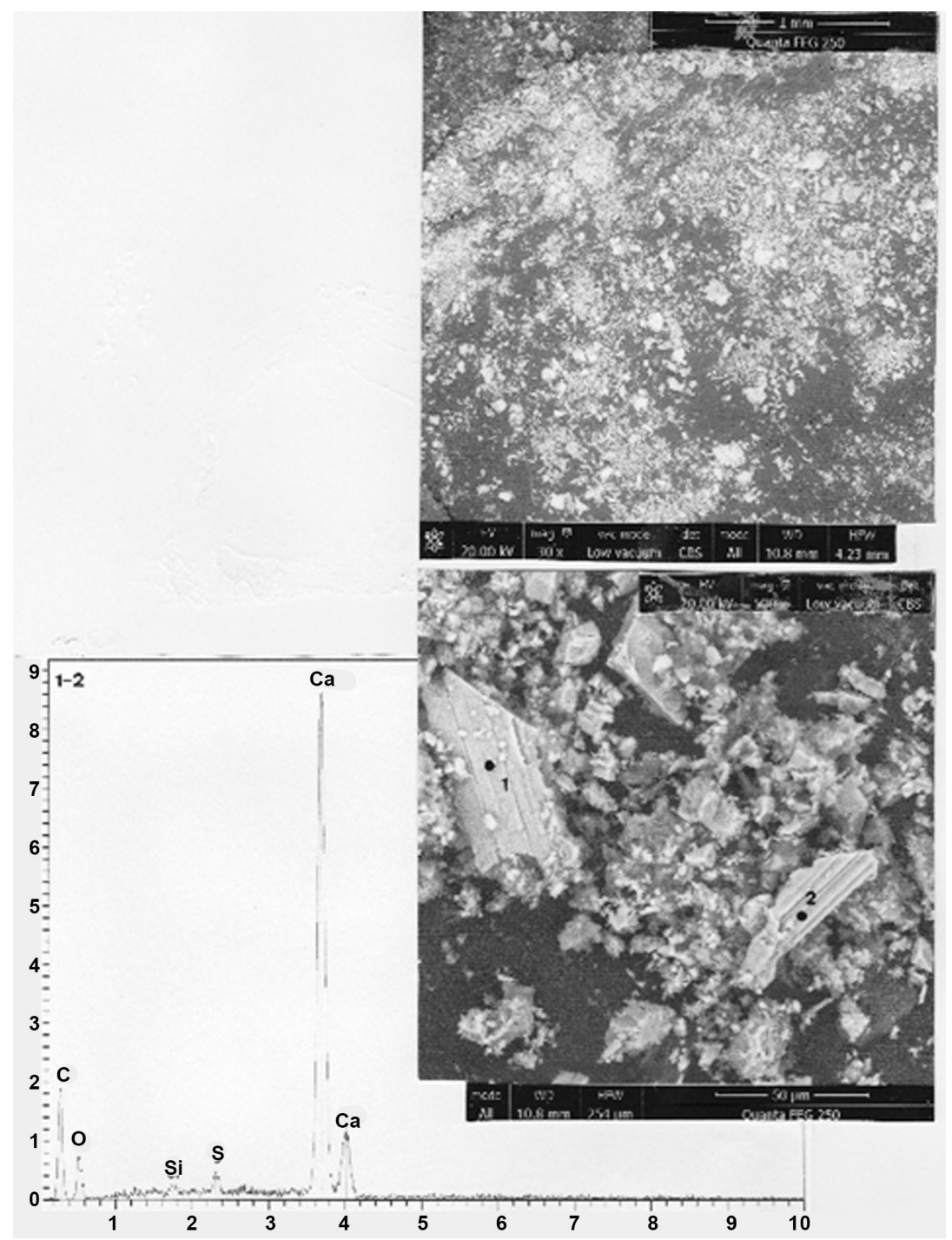

Figure 18. Study of the marble powder of Marie-Madeleine's sarcophagus. Upper photograph: SEM photograph (in CBS, 30x) of the powder. Lower photograph: SEM photograph (in CBS, 500×) of the powder; 1 and 2: two marble fragments. Below: spectrum of 1 and 2 at the black points. C: carbon; O: oxygen; Si (traces): silicium; S: sulphur; Ca (two peaks): calcium. 


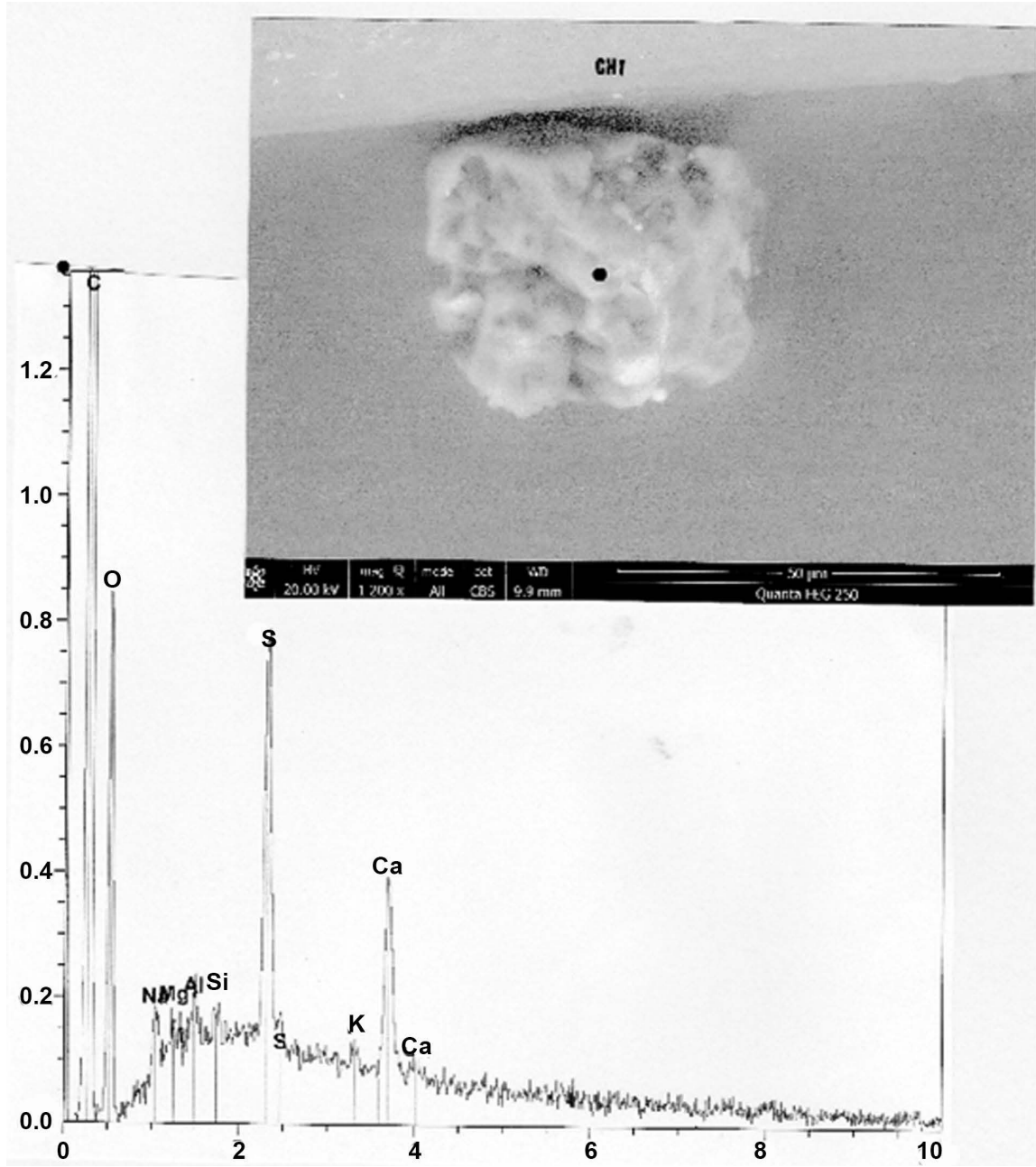

Figure 19. An example of an "alabaster" particle, located on hair number 1. Above: SEM photograph (in CBS, 1200x) of the particle, located on hair number 1 (CH1). Below. highly resolution spectrum at the black point. C: carbon; O: oxygen; Na: sodium; Mg: magnesium; Al: aluminium; Si: silicium; S (two peaks): sulphur; K: potassium; Ca (two peaks): calcium.

(found on the border of hair 1), have a mineral composition comparable to that of alabaster; but in fact it is a particle of chipboard gypsum $\left(\mathrm{CaSO}_{4} \cdot 2 \mathrm{H}_{2} \mathrm{O}\right)$, commonly found on hairs [10] (particle 2 of Figure 13 is an example) and indicative of the past marine environment to which they were exposed.

Figure 20 summarizes the study of an alabaster fragment (that of an alabaster lamp), which shows similarities between the spectra of gypsum alabaster and of gypsum.

\section{Conclusions}

The most interesting argument supporting the authenticity of Maria-Magdalena's hair, is the observation on their surfaces of marble fragments (as that shown in Figure 2) that can originate from the walls of the sarcophagus where her remains are kept. 


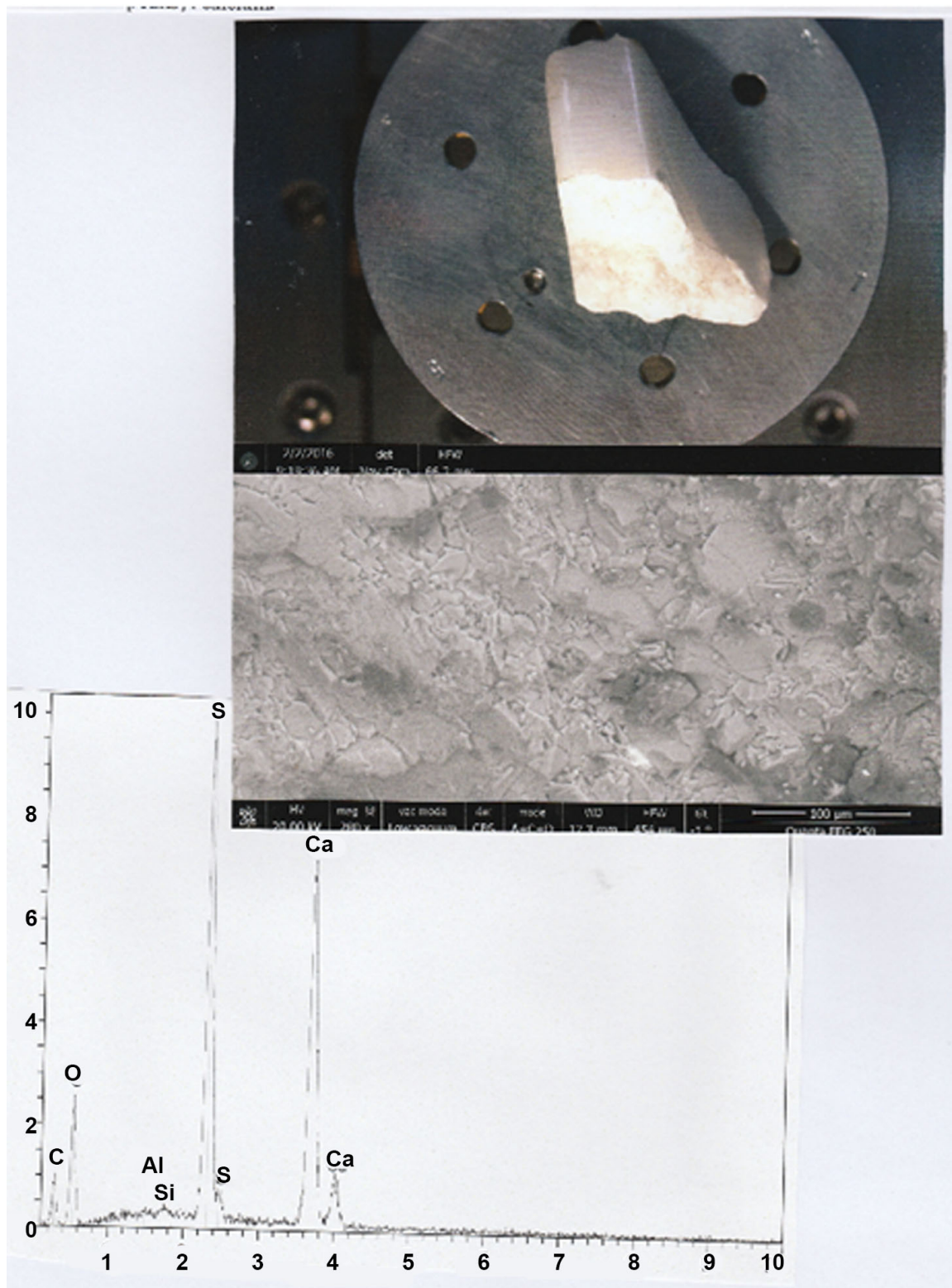

Figure 20. Study of an alabaster sample of reference. Upper photograph: optical view (3x) of the sample. Lower photograph: SEM photograph (in CBS, 280 $\times$ ) of the sample surface. Below. global spectrum of the sample. C: carbon; O: oxygen; Al (traces): aluminium; $\mathrm{Si}$ (traces): silicium; S (two peaks): sulphur; $\mathrm{Ca}$ (two peaks): calcium.

Interestingly also, is the other observation on hair surfaces of large plaques of iron-rich aluminosilicate (as that shown in Figure 6) that could originate from ancient brick fragments of tiles that covered some part of Maria-Magdalena's sarcophagus in the past.

By "authenticity" of these hairs, I simply mean that we found that they are conform to the French Tradition des Saints de Provence [1]. We have recently published three other argumentations in favour to this sort of authenticity:

They are common pollens and leafs and stem fragments of fennel on the surface of some of these hairs [11]; that agree to the tradition. 
The hair surfaces of most of these hairs are closely linked to osseous remains [12], which establish that they were in tight contact with the cranium of Maria-Magdalena during the preservation of the relic.

Some of the hair-surfaces are covered with gold and silver particles [12], that correspond to ornamentation and/or close contact to past-reliquaries.

Other mineral particles found here on hairs are of calcite (the most common calcium carbonate form found on samples) and of montmorillonite/illite (the most frequent aluminosilicate with iron from hot region soils). The frequently found dolomite particles on the hair surfaces can be related to the dolomitic geology of the Sainte-Baume region and surroundings. We found also on the hair surfaces some rare particles of quartz and potassium feldspar that were probably used for decorative/sanctifying reasons.

\section{Acknowledgements}

We thank Florian Racine, the priest of Saint-Maximin basilica, who furnished the Maria-Magdalena's hairs, and Françoise Sur, Présidente of the Association "Les Amis de la Basilique", who sent us some samples of the sarcophagus walls that are located in the crypt. Thanks also to Thierry Thomasset (UTC of Compiègne) for his assistance on the SEM. The present article is a development of my presentation at the Saint-Maximin basilica conference on the 23rd of July 2016.

\section{Conflicts of Interest}

The author declares no conflicts of interest regarding the publication of this paper.

\section{References}

[1] Trouillet, M.C. (2016) Les Reliques de Ste Marie-Madeleine. Petrus, Aix en Provence.

[2] Lucotte, G. (2016) The Mitochondrial DNA Mitotype of Sainte Marie-Madeleine. International Journal of Sciences, 5, 10-19. https://doi.org/10.18483/ijSci.1167

[3] Lucotte, G. and Thomasset, T. (2017) Study of the Red Colour of Ste Marie-Madeleine's ( $\approx 3-63$ ) Hair by Scanning Electron Microscopic Characterization of its Melanosomes. Journal of Dermatology and Pigmentation Research, 1, 1-9.

[4] Franzoni, A. (2015) Sainte Marie-Madeleine et les Saints de Provence dans la Tradition Provençale, Vol. 2. Editions ASTSP, Plan d'Aups Sainte-Baume.

[5] Charlier, P., Froesch, P., Benmoussa, N., Morin, S., Augias, A., Ubelmann, Y., Weil, R., Morin, S., Staub, F. and Deo, S. (2019) Computer-Aided Facial Reconstruction of "Mary-Magdalena" Following Hair and Skull Analyses. Clinical Medecine Insight Ear Nose Throat, 12, 1-20. https://doi.org/10.1177/1179550618821933

[6] Franbourg, A., Leroy, F. and Braïda, D. (2005) Evaluation of Product Efficacy. In: Bouillon, C. and Wilkinson, J., Eds., The Science of Hair Care, Taylor and Francis, New York, 377-454. https://doi.org/10.1201/b14191-13

[7] Fixot, M. (2009) La Crypte de Saint-Maximin-La-Sainte-Baume. Edisud, Aix-en-Provence.

[8] Welton, J.E. (2003) SEM Petrology Atlas. AAPG Publications, Tulsa, Oklahoma. 
[9] Schreiner, M., Melcher, M. and Uhlir, K. (2007) Scanning Electron Microscopy and Energy Dispersive Analysis: Applications in the Field of Cultural Heritage. Analytical and Bioanalytical Chemistry, 387, 737-747. https://doi.org/10.1007/s00216-006-0718-5

[10] Lucotte, G., D'Hérisart, E. and Thomasset, T. (2019) Marine Micro-Remains on Holy Maria-Magdalena's Hair, Studied by Scanning Electron Microscopy and Elemental Analysis. Archaeological Discovery, 7, 155-191.

https://doi.org/10.4236/ad.2019.73009

[11] Lucotte, G., Thomasset, T. and Salmon, A. (2018) Fennel (Foeniculum vulgare) Rests on the Holy Maria-Magdalena's Hairs, Studied by Scanning Electron Micrscopy and Elemental Analysis. Archaeological Discovery, 6, 216-270. https://doi.org/10.4236/ad.2018.63012

[12] Lucotte, G. (2019) Silver and Gold on the Hairs of Holy Maria-Magdalena, Studied by Scanning Electron Microscopy and Elemental Analysis. Archaeological Discovery, 7, 257-282. https://doi.org/10.4236/ad.2019.74012 